\title{
PERSEPSI DAN DAMPAK KEBUDAYAAN MA' NENEK TERHADAP IMAN KRISTEN JEMAAT GPSDI LEMBANG BUNTUMINANGA, KECAMATAN BUNTUPEPASAN, KABUPATEN TORAJA UTARA
}

\author{
Ivonne Sandra Sumual ${ }^{1}$, Rini Trivosa ${ }^{2}$ \\ ${ }^{1}$ Sekolah Tinggi Teologi Bethel Indonesia, ivonnesandra@sttbi.ac.id \\ ${ }^{2}$ Sekolah Tinggi Teologi Bethel Indonesia, rinitrivosa@gmail.com
}

\begin{abstract}
The encounter of the Christian faith with local culture produces dynamic interactions. It can happen that the Christian faith is integrated with that culture. Christian faith can also replace local culture. This is proven when the Christian faith meets the Ma 'nenek culture in Toraja. This research was conducted to find out how the perception and impact of Ma' nenek culture on the Christian faith of the GPSDI Buntuminanga congregation, Toraja. By using a qualitative approach or method, it was found that even though this village became a Christian enclave (100\% Christian), it turned out that they still believed in local cultures. These things state that some of the local people are Christians who practice syncretism, that is, there are 2 objects of belief or mixed beliefs. In addition there is also occultism, namely belief in the power of darkness. The presence of $\mathrm{Ma}^{\prime}$ nenek has attracted the attention of the community, especially in Lembang Buntuminanga, that the spirits of the ancestors will come to bless, heal, help and save for families who perform this ritual. The purpose of this culture is as a form of respect for parents. There are still some Christians in Toraja who still believe in the efficacy of rituals in the Ma' nenek. However, in general, $M a^{\prime}$ nenek is run by not crashing into the Christian faith in GPSDI Lembang Buntuminaga.
\end{abstract}

Keywords: grandmothers' culture; christian faith; respect for parents

\begin{abstract}
Abstrak
Pertemuan iman Kristen dengan kebudayaan lokal menghasilkan interaksi yang dinamis. Dapat terjadi bahwa iman Kristen menyatu dengan budaya tersebut. Dapat terjadi juga iman Kristen menggantikan budaya setempat. Hal tersebut yang nampak ketika iman Kristen bertemu dengan kebudayaan $M a$ ' nenek di Toraja. Penelitian ini dilakukan untuk mengetahui bagaimana persepsi dan dampak kebudayaan $M a^{\prime}$ nenek terhadap iman Kristen jemaat GPSDI Buntuminanga, Toraja. Dengan menggunakan pendekatan atau metode kualitatif, maka didapatkan bahwa sekalipun desa ini menjadi kantong Kristen (100\% Kristen), tetapi ternyata mereka masih menganut kepercayaan terhadap budaya-budaya lokal. Hal-hal tersebut menyatakan bahwa sebagian dari masyarakat setempat merupakan orang Kristen yang menjalankan sinkretisme, yakni terdapat 2 objek kepercayaan atau percampuran keyakinan. Di samping itu juga terdapat okultisme, yakni kepercayaaan terhadap kuasa kegelapan. Kehadiran Kebudayan $M a^{\prime}$ nenek telah menarik perhatian masyarakat khususnya di lembang Buntuminanga, bahwa arwah dari leluhur akan datang memberkati, menyembuhkan, menolong dan menyelamatkan bagi keluarga yang melakukan ritual ini. Tujuan dilakukannya kebudayaan ini adalah sebagai bentuk penghormatan terhadap Orang Tua. Masih ada beberapa orang Kristen di Toraja masih percaya dengan keampuhan ritual dalam budaya $M a^{\prime}$ nenek. Namun, secara umum, kebudayaan $M a^{\prime}$ nenek dijalankan dengan tidak menabrak iman Kristen di GPSDI Lembang Buntuminaga.
\end{abstract}

Kata Kunci: kebudayaan ma' nenek; iman kristen; penghormatan terhadap orang tua 


\section{PENDAHULUAN}

Setiap manusia yang hidup di suatu tempat pasti terikat dengan kebudayaan yang dipercayai di tempat tersebut. Sadar atau tidak sadar, hampir semua dari agenda aktivitas manusia selalu bersentuhan dengan kebudayaan. Dalam bukunya yang berjudul “Upacara Rambu Solo' di Tanah Toraja," Robi Panggarra mengatakan bahwa tidak ada kehidupan manusia yang tidak memiliki kebudayaan sebagai bagian dari ciri khas mereka, ${ }^{1}$ sehingga kebudayaan dan masyarakat diibaratkan dua sisi mata uang yang tidak bisa dipisahkan. Kebudayaan yang diciptakan oleh manusia ini memiliki keberagaman. Hal ini menyebabkan antara individu dengan individu lain, kelompok dengan kelompok, suku dengan suku dan sebagainya memiliki kebudayaan yang berbeda-beda. Akibatnya, setiap kelompok, suku, daerah mengungkapkan diri dengan cara mereka masing-masing. Perbedaan secara umum terlihat dari gaya bahasa, cara komunikasi, bentuk rumah, pandangan terhadap sesuatu, kebiasaan, ide, kepercayaan, adat-istiadat, organisasi sosial, nilai-nilai serta sejarah kebudayaan masing-masing. ${ }^{2}$

Sisi lain yang dipercayai oleh sebagian besar masyarakat bahwa kehadiran agama dalam kehidupan manusia masih tetap berdampingan dengan kebiasaankebiasaan yang diwariskan oleh leluhur mereka. Seperti, harus teliti dalam memilih hari untuk melakukan sebuah acara, perjalanan, dan menanam, karena bagi mereka ada hari yang baik dan ada hari yang buruk. Bagi suku Toraja sendiri ditemukan banyak larangan-larangan atau dikenal dengan sebutan pamali, yang sampai saat ini masih dianut oleh masyarakat Toraja. Sehingga dalam praktek kehidupan seharihari ditemukan banyak aktifitas ritual orang Kristen yang seolah-olah bersinggungan dengan iman Kristen. Dengan demikian tidak menutup kemungkinan bahwa sebuah kebudayaan atau ritual yang masih dilakukan akan memberikan pengaruh yang akan membawah kepada tingkat kepercayaan terhadap budaya tersebut dengan harapan kehidupan mereka akan jauh lebih baik.

\section{METODE PENELITIAN}

Pada dasarnya metode adalah cara ilmiah untuk mendapatkan data dengan kegunaan tertentu. ${ }^{3}$ Menurut Cholid Narkubo dan Ahmadi, metode merupakan cara yang tepat untuk melakukan suatu dengan menggunakan pikiran secara seksama dalam mencapai tujuan. ${ }^{4}$ Adapun pendekatan atau metode yang digunakan peneliti dalam penelitian ini adalah kualitatif. Menurut Sugiono, metode penelitian kualitatif adalah metode penlitian yang berlandaskan pada filsafat postpositivism, digunakan untuk meneliti pada kondisi obyek yang almiah, dimana penliti sebagai instrument kunci, teknik pengumpulan data dilakukan secara 
triangulasi (gabungan), analisis data bersifat induktif/kualitatif, dan hasil penelitian kualiatatif lebih menekankan makna dari pada generalisasi. ${ }^{5}$

Metode kualitataf terbagi atas 3 bagian metode, yaitu observasi/pengamatan, metode yang baik untuk dilakukan dalam sebuah penelitian. Validitas data yang diperoleh peluangnya lebih besar karena melalui observasi peneliti belajar tentang perilaku dan makna dari perilaku tersebut. ${ }^{6}$ Dalam penelitian ini, peneliti menggunakan model observasi "terus terang" atau "tersamar." Dalam hal ini peneliti akan melakukan pengumpulan data dan menyatkan terus terang kepada sumber data, bahwa peneliti sedang melakukan penelitian. Yang kedua adalah wawancara, yaitu dialog langsung peneliti dengan responden penelitian. Dalam wawancara tersebut, akan ditanyakan beberapa pertanyaan kepada narasumber yang sudah dipilih sebelumnya. Dan ketiga adalah dokumentasi yaitu teknik yang digunakan oleh peneliti supaya setiap data yang yang diperoleh dapat dipercaya dan memungkinkan peneliti untuk melihat setiap informasi pengumpulan data yang ada sehingga dapat menjadi pedoman untuk membuat suatu perubahan dalam sebuah penelitian yang ada.

Setelah data terkumpul, maka langkah selanjutnya adalah menganalisis data tersebut. Analisa data adalah proses mengatur urutan data, mengorganisasikan kedalam satu pola, kategori dan satu uraian dasar. Penelitian ini menggunakan penelitian kualitatif, sehingga dalam menganalisi data yang terkumpul peneliti menggunakan analisis deskriptif. Dimana analisis yang dilakukan adalah sebuah penjelasan yang dibuat dari jawaban hasil wawancara (data) yang disertai dukungan data hasil wawancara. Dengan adanya metode deskriptif kualitatif, maka teknik analisa data dilakukan dengan 3 tahapan, yaitu: ${ }^{7}$

a. Reduksi data, yaitu proses pemilihan, pemadatan perhatian pada penyederhanaan, pengabstrakan, dan transformasi data mentah atau data kasar yang muncul dari catatan-catatan tertulis di lapangan.

b. Penyajian data, yaitu penyusunan informasi yang kompleks ke dalam suatu bentuk yang sistematis, sehingga menjadi lebih selektif dan sederhana serta memberikan kemungkinan adanya penarikan kesimpulan data dan pengambilan tindakan.

c. Kesimpulan, yaitu tahap akhir dalam proses analisa data, pada bagian ini peneliti mengutarakan kesimpulan dari data-data yang telah diperoleh.

\section{PEMBAHASAN}




\section{Pengertian Kebudayaan $M a^{\prime}$ nenek}

Menurut Kevin J. Vanhoozer, kebudayaan adalah system yang diekspresikan dalam bentuk-bentuk obyektif, hal- hal yang diterima oleh suatu masyarakat sebagai nilai-nilai yang mengarahkan dan menopang kehidupan manusia. ${ }^{8}$ Selain itu, kebudayaan menurut Irwan, kebudayaan merupakan blue-print yang telah menjadi kompas dalam perjalanan hidup manusia, dan menjadi pedoman dalam tingkah laku. ${ }^{9}$

Kebudayaan secara historis menurut Kroeber dan Kluckhohn merupakan warisan yang dialih-turunkan dari gererasi satu ke generasi berikutnya. ${ }^{10}$ Kebudayaan adalah seluruh proses kegiatan manusia. Sehingga dapat di uraiakan bahwa salah satu ciri pokok dari kebudayaan adalah kebudayaan terjalin erat dengan kehidupan manusia dalam masyarakat. Kebudayaan selalu bersifat kemasyarakatan. ${ }^{11}$

$M a '$ nenek merupakan bagian dari kebudayaan Rambu Solo' (upacara kedukaan). Meskipun demikian, $M a$ ' nenek tetap memiliki upacara tersendiri. Dalam perkembangannya $M a$ ' nenek menjadi sebuah kebudayaan yang penting sehingga rutin dilakukan oleh masyarakat Toraja, khususnya masyarakat Baruppu', Sesean Suloara', Buntupepasan, dan Rindingallo. Keempat kecamatan ini akan bergantian untuk melakukan kebudayaan tersebut. Meskipun tidak dilakukan secara bersamaan, namun tetap pelaksanaanya selama bulan Agustus.

Kebudayaan $\mathrm{Ma}^{\prime}$ nenek adalah sebuah upacara mengganti busana/pakaian para leluhur yang sudah meninggal dengan pakaian atau busana yang baru. Sebenarnya bukan hanya membersihkan mayat namun juga membersihkan halaman atau sekitaran kuburan tersebut. Menurut Yunus Yan, $M a$ ' nenek adalah sebuah upacara membersihkan kuburan, menanam bunga dan membungkus orangtua, kakek/nenek, anak, ataupun saudara yang sudah meninggal. ${ }^{12}$

Secara etimologi kata, Ma' nenek berasal dari dua kombinasi kata bahasa Toraja. $M a^{\prime}$ adalah sebuah kata depan penghubung dalam bahasa Toraja yang menjelaskan sesuatu yang akan dilakukan. Sedangkan Nenek tidak hanya mengacu kepada "nenek (perempuan)" tetapi sebagai "kakek atau nenek" dalam artian Nenek yang dimaksudkan disini adalah leluhur. Luther Balalembang dalam bukunya yang berjudul $A d a$ ' Toraya, mengatakan bahwa ada tiga alasan kenapa orang melakukan upacara $M a^{\prime}$ nenek, yaitu:

a. Ada orang yang melakukan kebudayaan $M a$ ' nenek karena pada waktu upacara kematiannya keluarga atau kerabat yang meninggal, kurban yang diberikan tidak cukup.

b. Ada orang yang melakukan kebudayaan $\mathrm{Ma}^{\prime}$ nenek 
karena ia selalu beruntung

dalam mencari nafkah.

c. Ada orang yang melakukan kebudayaan $M a$ ' nenek karena ia sembuh dari penyakitnya. ${ }^{13}$

Tetapi pada umumnya, masyarakat Toraja melakukan adat ini sebagai bentuk penghormatan dan kasih sayang kepada orangtua, saudara, kerabat, dan lainnya yang sudah meninggal serta mengharapkan leluhur mengingat keluarga yang masih hidup, agar diberikan kebaikan. Hal inilah yang menjadi alasan kenapa adat ini dipertahankan dan rutin dilakukan. Mahmuddin dalam skripsinya mengatakan bahwa: "The purpose of conducting Ma"nene ceremony, is to give offering to ancestor. The ceremony is aimed to celebrated ancestor considered have given blessing to his offspring." 14 Artinya bahwa tujuan dari adat $M a^{\prime}$ nenek adalah untuk memberikan persembahan kepada leluhur. Upacara ini bertujuan untuk dirayakan sebab leluhur dianggap telah memberikan berkat kepada keturunannya. Selain itu, mereka juga menganggap adat ini sebagai bentuk kasih sayang mereka kepada leluhur dan mempercayai bahwa memanusiakan orang yang sudah meninggal adalah perbuatan yang mulia. ${ }^{15}$

\section{Konsep Iman Kristen}

Dalam Perjanjian Lama, iman berasal dari kata "aman" yang berarati "memegang teguh," 16 di mana kata ini diartikan secara luas bahwa Allah harus dianggap sebagai Yang teguh dan Yang kuat. Sehingga Perjanjian Lama mengambil sebuah kesimpulan bahwa, beriman kepada Allah berarti mengamini bukan hanya dengan akalnya tetapi juga dengan segenap kepribadiannya dan cara hidupnya kepada segala janji yang diberikan dengan perantaraan Firman dan karyaNya.

Sedangkan menurut Perjanjian Baru, iman adalah mengamini dengan segenap kepribadian dan cara hidupnya kepada janji Allah bahwa Ia di dalam Kristus telah mendamaikan orang berdosa dengan diriNya sendiri, sehingga hidup seseorang tersebut dikuasai oleh keyakinan. ${ }^{17}$

Iman adalah syarat mutlak untuk mendapatkan anugerah keselamatan (Ef. 2:8-9). Tanpa iman mustahil seseorang dapat berkenan kepada Allah (Ibr. 11:6). Tanpa iman kehidupan rohani kita mati (Rm. 1:17). Dalam hal ini iman sebagai sarana yang dengannya kita diselamatkan (10:9). Bukan iman yang menyelamatkan, tetapi objek dari iman tersebut, yaitu Yesus Kristus. Dengan demikian iman sebagai jembatan untuk memperoleh anugerah keselamatan dari Yesus Kristus. Yesus harus menjadi objek iman itu sendiri, barulah iman tersebut membawa kepada keselamatan.

Menurut John Murray, iman adalah sebuah aktivitas yang utuh dilakukan oleh pihak manusia dan hanya di pihak manusia 
saja. ${ }^{18}$ Sedangkan Sinclair B. Ferguson dalam bukunya mengatakan bahwa iman memainkan peran sentral dalam kehidupan umat Allah yang hidup di bawah kovenan Allah. ${ }^{19}$ Iman Kristen adalah iman yang berkeyakinan, bahwa Tuhan Allah di dalam Tuhan Yesus Kristus telah mendamaikan manusia dosa dengan diriNya sendiri. ${ }^{20}$

Untuk bisa mengerti iman Kristen dan misi dari iman, maka membutuhkan penguraian secara sistematis. Dalam hal ini iman Kristen harus berpusat pada Alkitab. Karena Kristus sebagai Juru Slamat yang telah mendamaikan manusia dengan diriNya, dapat diketahui manusia dari Alkitab. Menurut Harun Hadiwijono, bagi iman Kristen Alkitab bukan Kitab UndangUndang melainkan Kitab yang hidup, yang setiap saat dipakai oleh Tuhan untuk berfirman kepada umatNya. $^{21}$ Menurut Erastus Sabdono, semua yang tertulis di dalam Alkitab memuat kebenaran Firman Tuhan; dan semua harus diterima dan diyakini sebagai kebenaran. ${ }^{22}$

Dengan demikian, memperkenalkan isi iman Kristen sudah menjadi barang tentu menjadi kewajiban gereja. Dimana wujud dari iman itu sendiri dapat dilihat dari kehidupan sehari-hari warga gereja dalam lingkungannya. Isi pokok iman Kristen adalah karya penyelamatan Allah terhadap manusia sehingga manusia dapat bersekutu denganNya. Ini merupakan sebuah karya yang besar sehingga karya ini mencakup bagian-bagian yang banyak sekali. Menjadi sebuah penegasan bahwa karya Allah yang besar ini di kenal dari Alkitab. Sebab semua karya dan diriNya diperkenalkan kepada manusia dari jaman ke jaman melalui Alkitab.

\section{Penghormatan terhadap orang tua menurut iman Kristen}

Dari kesepuluh hukum Taurat yang diberikan oleh Allah kepada Musa, salah satu perintah yang di berikan adalah menghormati orang tua. Hal ini membuktikan bahwa perintah untuk menghormati orang tua merupakan hal yang sangat penting. Perintah untuk menghormati orang tua merupakan perintah ke-5 yang di tuliskan dalam Keluaran 20:12. Menghormati orang tua bukanlah hal yang baru bagi orang Kristen. Istilah "hormat" dalam bahasa ibraninya adalah “kabad" atau "kabed". yang artinya menghormati, mengagungkan, memuliakan, menyenangkan. Dalam bahasa Yunaninya adalah dipakai kata "timao" yang artinya: honour atau menghormati,value atau menghargai. ${ }^{23}$ Kesimpulannya arti "hormatilah" adalah menghargai, menghormati, dan memuliakan bukan memburukkan namanya.

Menghormati orang tua atau mengabdi terhadap orang tua sudah dilakukan sejak dini. Mulai dari masa pertumbuhan anak, orang tua sudah memiliki kewajiban untuk membimbing dan mendidik anak bagaimana untuk 
menghormati orang tuanya atau orang yang lebih tua darinya (Ams. 23:22,24-25). Dalam hal ini, bukan hanya anak yang di tuntut untuk menghormati orang tuanya, tetapi orang tua yang baik juga akan mengasihi anaknya dan tidak membiarkan anaknya untuk berjalan sendiri dalam kehendaknya, melainkan mendidiknya dengan benar. ${ }^{24}$

Pada saat Allah memberikan perintah untuk menghormati orang tua, maka ada berkat yang akan diterima oleh sang anak jika perintah ini dilakukan dengan benar. Berkat tersebut adalah lanjut umur. Umur panjang akan menjadi bagian bagi orang yang menghormati orang tuanya. Kitab Amsal banyak memberikan penekanan terhadap anak yang harus menghormati dan taat kepada orang tuanya (Ams. 1:8-9; 13:1; $15: 20 ; 4: 1) .{ }^{25}$ Jika menghormati orang tua adalah hal yang baik dan menjadi berkat bagi setiap anak yang menurutinya, maka apa yang akan terjadi atau apa yang akan diterima oleh anak yang tidak menghormati orang tuanya? Dalam Keluaran 21:17 dituliskan, bahwa "siapa yang mengutuki Ayahnya atau Ibunya, ia pasti dihukum mati." Hukuman mati yang dilakukan dengan cara dilempari batu (U1. 21:18-21b). Jelas bahwa menghormati orang tua adalah sebuah jembatan untuk mencapai berkat yang paling besar yaitu umur panjang. Selain itu dalam Efesus 6:2-3 tertulis bahwa anak yang menghormati orang tua akan berbahagia. Sebaliknya, tidak menghormati orang tua maka kematian menjadi bagian anak tersebut.

Tujuan masyarakat Toraja melakukan kebudayaan $\mathrm{Ma}^{\prime}$ nenek adalah sebagai bentuk penghormatan mereka kepada orang tua yang sudah melahirkan dan membesarkan mereka. Sehingga ketika mereka telah meninggal, maka mereka pun layak menerima penghormatan dari anak atau keluarga mereka.

J. Verkuyl menuliskan ada tiga motif orang melakukan pemujaan kepada nenek moyang/ orang tua. Pertama, karena adanya perasaan hormat dan cinta kasih serta rasa terimakasih atas segala yang telah diterima dari orang tua atau para leluhur. Kedua, adanya perasaan takut, jika arwah nenek moyang akan membalaskan jika ia kurang memuja. Ketiga, untuk kepentingan sendiri. Melalui pemujaan ini orang seolah-olah memaksa arwah nenek moyang atau orang tua supaya memberi berkat dan perlindungan kepadanya. ${ }^{26}$

Sebagai pertimbangan peneliti bahwa pemujaan kepada arwah nenek moyang, dalam bentuk apapun juga merupakan suatu pelanggaran terhadap firman atau hukum pertama, yang mengatakan "Jangan ada padamu Allah lain dihadapan-Ku." Di dalam pemujaan itu yang didewakan adalah arwah manusia. Dalam hal ini theosentris menjadi anthroposentris. Kepada yang bukan Allah disampaikan sesuatu yang sebenarnya hanya layak bagi Allah, yakni:korban persembahan. ${ }^{27}$ 
Ketika iman Kristen diperhadapkan dengan kebudayaan penghormatan terhadap orang tua yang telah mininggal, maka penghormatan terhadap orang tua atau leluhur yang baik adalah kebudayaan yang sesuai dengan kehendak dan perintah Allah. Dalam etika Kristen, kebudayaan ini bersangkutan dengan tujuan kebudayaan. Tujuan kebudayaan menurut Verkuyl adalah untuk menyatakan kasih kepada Allah dan mengabdi kepada Allah. ${ }^{28}$ Dalam hal ini kebudayaan diciptakan untuk memuliakan Allah. Dengan demikian, penghormatan terhadap orang tua atau leluhur harus memiliki tujuan yang sama yaitu menyatakan kasih dan mengabdi kepada Allah.

Dalam hal-hal tertentu, Yesus melawan adat istiadat atau kebudayaan yang dilatar belakangi oleh sesuatu yang sifatnya melawan atau tidak mempermuliakan Allah. Sebab Yesus adalah di atas kebudayaan atau melintasi kebudayaan, di mana Yesus tidak bisa dibatasi oleh satu kebudayaan bahkan semua kebudayaan. ${ }^{29}$ Yesus tidak pernah dan tidak akan menyesuaikan diri-Nya dengan kebudayaan manapun juga sekiranya tidak sesuai dengan FirmanNya. ${ }^{30}$

Dalam firman Allah yang kelima, Tuhan memberikan suatu perintah kepada kita untuk menghormati orang tua kita. Mengasihi dan patuh kepada mereka dalam keadaan apapun, mengabdi kepada mereka dimasa hidupnya kurang atau tidak berdaya lagi karena sakit ataupun lanjut usia, umat Allah harus tetap melayani dan menghormati mereka. ${ }^{31}$ Tetapi cinta kasih kepada orang tua itu sekali-kali tidak boleh melebihi ataupun menggantikan cinta kasih kepada Tuhan. ${ }^{32}$

Iman Kristen menolak kebudayaan yang menyembah dan menghormati segala sesuatu yang melebihi Allah, seperti benda, ilah-ilah,arwah dan sebagainya baik dalam pikiran, perkataan, ataupun perbuatan. Kadang kala keberadaan dosa tidak disadari saat melakukan kebudayaan tertentu. Dosa bukan hanya terlihat dalam hasil kebudayaan namun juga penggunaan kebudayaan. ${ }^{33}$

Dengan demikian peneliti mempertimbangkan bahwa penghormatan terhadap orang tua yang dilakukan oleh masyarakat dan jemaat GPSDI Buntuminanga sebagai tujuan dari kebudayaan $M a$ ' nenek, tidak dalam batasan-batasan yang sesuai dengan iman Kristen. Dalam hal ini penghormatan terhadap orang tua harus dipahami secara luas dan benar, dimana masyarakat atau jemaat harus memahami bahwa menghormati orang tua bukan hanya dilakukan ketika mereka telah meninggal. Namun selama hidup mereka pun harus dihormati, dikasihi dan diberikan perhatian yang khusus. Refael Christian dalam skripnya mengutip pernyataan dari Legge, "That parents, when alive, should be served 
according to propriety; when dead, they should be buried according to propriety; and that they should be sacrifided to according"34 yang dimaksudkan adalah ketika masih hidup, orang tua harus dilayani dengan penuh penghormatan, ketika sudah meninggal orang tua harus dikuburkan dengan penuh penghormatan juga, dan ketika memberikan korban sajian dengan penuh penghormatan. Sehingga firman Tuhan dalam Keluaran 20:12 "Hormatilah Ayahmu dan Ibumu ditanah yang di berikan TUHAN, Allahmu, kepadamu..." boleh tergenapi dan akan menjadi berkat bagi anak yang menghormati orang tuanya. Bakti atau hormat kepada orang tua pun merupakan salah satu bentuk kita mengasihi Allah, karena kita menaati perintahNya.

\section{KESIMPULAN}

Budaya merupakan salah satu unsur yang penting dalam kehidupan masyarakat. Sekalipun budaya yang diciptakan oleh manusia memiliki keberagaman, akan tetapi tidak bisa dipungkiri bahwa kehadiran kebudayaan dalam kehidupan manusia telah memberikan dua sisi yang berbeda, baik sisi positif maupun sisi negatif.

Kebudayaan $M a$ ' nenek adalah salah satu budaya yang unik di mana memiliki esensi yang mendalam bagi masyarakat Toraja secara umum. Dalam konsep pemahaman mereka, kebudayaan ini adalah salah satu adat yang diturunkan oleh leluhur, sehingga tidak akan pernah bisa untuk dihilangkan. Sesuai dengan kepercayaan mereka, bahwa apa yang diturunkan oleh leluhur adalah hal yang baik, dan jika hal itu ditolak atau dihilangkan, maka ini merupakan sebuah bentuk pemberontakan atau ketidakhormatan kepada leluhur. Dalam hal ini peneliti menemukan bahwa ritual ini masih memiliki daya tarik yang kuat bagi masyarakat Toraja, sekalipun sudah hidup dalam keKristenan.

Selain itu dari hasil wawancara yang peneliti lakukan, maka peneliti menemukan bahwa Kebudayaan $M a^{\prime}$ nenek adalah suatu ritual yang telah memberikan pengaruh kepada iman Kristen jemaat GPSDI Buntuminanga, sekalipun dampak yang yang diberikan tidak terlalu besar. Hal ini dapat dilihat dari hasil wawancara dengan narasumber bahwa ritual Ma' nenek ini, sekalipun sudah dilakukan secara keKristenan menurut paham narasumber yang melakukan, namun peneliti melihat sisi lain bahwa perbedaan dalam ritual $M a$, nenek pada zaman Aluk Todolo dengan masa sekarang ini, hanya terletak pada proses peribadatan saja. Dalam hal ini narasumber yakin bahwa ritual ini sudah benar dan tidak memberikan pengaruh bagi iman mereka.

Menjadi sebuah alasan mendasar bagi narasumber bahwa ritual ini hanya sebatas ritual yang dilaksanakan untuk mengenang jasa pada orang tua, leluhur dan 
kerabat. Menurut pertimbangan narasumber bahwa makanan atau hewan kurban yang diberikan sudah tidak perlu dibawa ke kuburan lagi untuk dipersembahkan kepada arwah leluhur. Pun peneliti melihat bahwa persembahan dalam bentuk makanan memang sudah tidak dilakukan lagi, tetapi mengalami peralihan dari makanan kepada benda-benda tertentu, sepert uang, bunga, sirih, rokok, pakaian, dan lainnya. Sehingga peneliti beranggapan bahwa objek persembahan yang diberikan tidak mengalami perubahan sekalipun jenis persembahan yang diberikan berubah.

\section{DAFTAR PUSTAKA}

Choid, Narkubo dan Ahmadi. Metodelogi Penelitian. Jakarta: Bumi Aksara, 1997.

Ferguson B. Sinclair. Kehidupan Kristen. Surabaya: Momentum, 2007.

Hadiwijono, Harun. Iman Kristen. Jakarta: BPK Gunung Mulia, 1995.

https://amp-tirto-

id.cdn.ampproject.org/v/s/amp.tirto. id/makna-kematian-di-balik-ritus$\underline{\text { manene- }}$ cy $8 \mathrm{~h}$ ?amp is $\mathrm{v}=\mathrm{a} 2 \& \mathrm{amp}$ gsa $=1 \& \mathrm{u}$ $\underline{\text { sqp }}=$ mq331AQECAFYAQ $\% 3 \mathrm{D} \% 3$ D\#referrer $=\mathrm{https} \% 3 \mathrm{~A} \% 2 \mathrm{~F} \% 2 \mathrm{Fww}$ W.google.com\&amp $\mathrm{tf}=$ From $\% 20$ $\% 251 \% 24$ s\&ampshare $=$ https $\% 3 \mathrm{~A}$ \%2F\%2Famp.tirto.id\%2F\%2Fmakn a-kematian-di-balik-ritusma039nene-cy8h
Husaini, Usman dan Setiadi Purnama. Metodologi Penelitian Sosial. Jakarta: Bumi Aksara, 2000.

Irwan, Abdullah. Konstruksi dan Reproduksi Kebudayaan.

Yogyakarta: Pustaka Pelajar, 2015. Mamuddin. "The Meaning and Value of Ma' Nene Ceremony in Toraja Utara.” Skripsi Sarjana. Universitas Islam Alauddin, 2011.

Murray, John. Penggenapan dan Penerapan Penebusan. Surabaya: Momentum, 1999.

Niebuhr H. Richard Kristus dan Kebudayaan. Jakarta: Petra Jaya, 1949.

Niebuhr, Richard H. Kristus dan Kebudayaan. Jakarta Pusat: Petra Jaya.

Refael, Christian. Tinjauan Etis Terhadap Penghormatan Leluhur dalam Kebudayaan Tionghoa." Skripsi Sarjana. Jakarta: STT Bethel Indonesia, 2016.

Robi, Panggarra. Upacara Rambu Solo' di Tanah Toraja: Memahami Bentuk Kerukunan Di Tengah Situasi Konflik. IKPI, 2015.

Sabdono Erastus. Membuktikan Alkitab adalah Firman Tuhan. Jakarta: Rehobot Literatur, 2018.

Sihombing Lotnatigor. Kultus dan Kultur. Malang: Sekolah Tinggi Theologia “1-3” Batu, 1997. 
Sosipater, Karel. Etika Perjanjian Lama.

Jakarta: Suara Harapan

Bangsa,2016.

Sugiyono. Metode Penelitian Kombinasi

(Mixed Methods). Bandung:

Alfabetha, 2014.

Sugiyono. Metode Penelitian Kuantitatif

Kualitatif. Bandung: Alfabetha,

2008.

Surbakti, Elisa. B. Konseling Praktis.

Bandung: Yayasan Kalam Hidup,

2008.
Tumenggung May Adeline. Teori-Teori

Kebudayaan.

Yogyakarta:

KANISIUS, 2005.

Vanhoozer, Kevin J. God and Culture.

Surabaya: Momentum, 2002.

Verkuyl, J. P. Etika Kristen Kapita Selekta.

Jakarta: BPK Gunung Mulia, 1992.

Webster, D. Douglas. Kehidupan

Kristen dalam Kebudayaan Duniawi.

(Malang: Gandum Mas, 1980.

${ }^{1}$ Robi Panggarra, Upacara Rambu Solo' di Tanah Toraja: Memahami Bentuk Kerukunan Di Tengah Situasi Konflik, (IKPI, 2015), 1.

${ }^{2}$ H. Richard Niebuhr, Kristus dan Kebudayaan (Jakarta: Petra Jaya), 34-37.

${ }^{3}$ Sugiono, Metode Penelitian Kuantitatif Kualitatif(Bandung: Alfabetha, 2008), 2 .

${ }^{4}$ Choid Narkubo dan Ahmadi, Metodelogi Penelitian (Jakarta: Bumi Aksara, 1997), 7.

${ }^{5}$ Sugiyono, Metode Penelitian Kombinasi (Bandung: Alfabetha, 2008), 12-13.

${ }^{6}$ Ibid., 309.

${ }^{7}$ Husaini Usman dan Purnama Setiadi, Metodologi Penelitian Sosial (Jakarta: Bumi Aksara, 2000), 86.

${ }^{8}$ Kevin J. Vanhoozer, Allah dan Kebudayaan (Surabaya: Momentum, 2002), 8.

${ }^{9}$ Irwan Abdullah, Konstruksi dan Reproduksi Kebudayaan (Yogyakarta: Pustaka Pelajar, 2015), 1.

${ }^{10}$ Adeline May Tumenggung, Teori-Teori Kebudayaan (Yogyakarta: KANISIUS, 2005), 258.

${ }^{11}$ H. Richard Niebuhr, Kristus dan Kebudayaan (Jakarta: Petra Jaya, 1949), 37.

${ }^{12}$ Penjelasan yang didapat dari lembaga adat lembang Buntuminanga, Yunus Yan, pada tanggal 15 September 2018.

${ }^{13}$ Luther Balalembang, Ada' Toraya, 54.

${ }^{14}$ Mamuddin, "The Meaning and Value of Ma' Nene Ceremony in Toraja Utara" (Skripsi sarjana., Universitas Islam Alauddin, 2011), 18.

${ }^{15} \mathrm{https}: / / \mathrm{amp}$-tirto-id.cdn.ampproject.org/v/s/amp.tirto.id/makna-kematian-di-balik-ritus manenecy $8 \mathrm{~h}$ ?amp js_v=a2\&amp gsa=1\&usqp=mq331AQECAFYAQ\%3D $\% 3 D \#$ referrer=https $\% 3 \mathrm{~A} \% 2 \mathrm{FFwww}$.go ogle.com\&amp tf=From $\% 20 \% 251 \% 24$ s\&ampshare=https $\% 3 \mathrm{~A} \% 2 \mathrm{~F} \% 2 \mathrm{Famp}$.tirto.id $\% 2 \mathrm{~F} \% 2 \mathrm{Fmakna}$-kematian-dibalik-ritus-ma039nene-cy8h. Jurnal diakses pada tanggal 27 Oktober 2017.

${ }^{16}$ Harun Hadiwijono, Iman Kristen (Jakarta: BPK Gunung Mulia, 1995), 17.

${ }^{17}$ Ibid.

${ }^{18}$ John Murray, Penggenapan dan Penerapan Penebusan (Surabaya: Momentum, 1999), 131.

${ }^{19}$ Sinclair B. Ferguson, Kehidupan Kristen (Surabaya: Momentum, 2007), 82.

${ }^{20}$ Harun Hadiwijono, Iman Kristen, 24.

${ }^{21}$ Ibid., 19.

${ }^{22}$ Erastus Sabdono, Membuktikan Alkitab adalah Firman Tuhan (Jakarta: Rehobot Literatur, 2018), 5.

${ }^{23}$ Karel Sosipater, Etika Perjanjian Lama (Jakarta: Suara Harapan Bangsa, 2016), 91.

${ }^{24}$ Elisa B. Surbakti, Konseling Praktis (Bandung: Yayasan Kalam Hidup, 2008), 257.

${ }^{25}$ Karel Sosipater, Etika Perjanjian Lama, 92.

${ }^{26}$ J. Verkuyl, Etika Kristen: Kapita Selekta (Jakarta, BPK Gunung Mulia, 1992), 33.

${ }^{27}$ Ibid.

${ }^{28}$ Ibid., 23. 
${ }^{29}$ Lotnatigor Sihombing, Kultus dan Kultur, (Malang: Sekolah Tinggi Theologia “1-3” Batu, 1997), 101-

103.

${ }^{30}$ Douglas D. Webster, Kehidupan Kristen dalam Kebudayaan Duniawi, (Malang: Gandum Mas, 1980), 29.

${ }^{31}$ Karel Sosipater, Etika Perjanjian Lama, 93.

${ }^{32}$ J. Verkuyl, Etika Kristen: Kapita Selekta, 34.

${ }^{33}$ J. Verkuyl, Etika Kristen Kebudayaan, 25.

${ }^{34}$ Refael Christian, Tinjauan Etis Terhadap Penghormatan Leluhur dalam Kebudayaan Tionghoa ( Skripsi, STT Bethel Indonesia, 2016), 54. 